
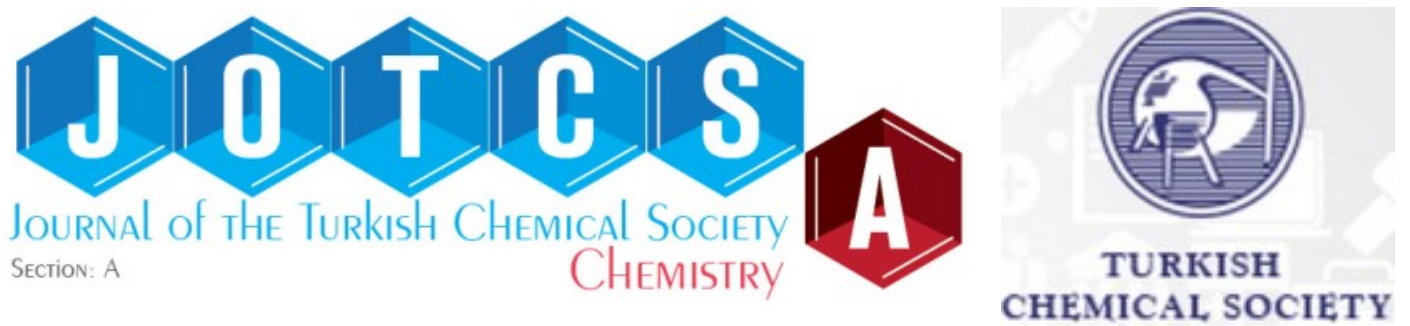

\title{
Chitosan-Graft-Polyacrylamide Based Release Systems: Effect of pH and Crosslinking
}

\author{
Ahmet KÜÇÜKÇALIK \\ Cüneyt H. ÜNLÜ* \\ Istanbul Technical University Science \& Letters Faculty, Chemistry Department Maslak TR34469 Istanbul \\ TURKEY
}

\begin{abstract}
This study covers the synthesis and release behavior of chitosan-graft-polyacrylamide copolymers in aqueous media at different $\mathrm{pH}$ values. The copolymers were synthesized using redox polymerization with ceric ammonium nitrate (CAN) in $1 \%$ aqueous acetic acid solution as the initiator. Optimum condition for the graft copolymer synthesis was determined as $3.85 \mathrm{~g} / \mathrm{L}$ chitosan, $0.27 \mathrm{M}$ acrylamide $(\mathrm{AAm})$ monomer at $40^{\circ} \mathrm{C}$ with a CAN per gram chitosan as $6 \mathrm{mmol}$ using $0.05 \mathrm{M}$ stock solution in $0.1 \mathrm{~N} \mathrm{HNO}_{3}$. Then the crosslinked copolymers were synthesized using methylenebisacrylamide (MBA) as a crosslinker varying mass proportions of AAm:MBA as 15:1, 20:1, and 30:1. Obtained material amount (polymer yield) and molecular weight of crosslinked copolymers were lower than the graft copolymer as expected. Acetylsalicylic acid (ASA) release behaviors of all copolymers were monitored with UV-visible spectroscopy at different $\mathrm{pH}$ values $(2,6$, and 8.5$)$ corresponding to different media in the body (stomach, skin, and intestine, respectively). According to the results, the release behavior changed the least among the samples with respect to medium $\mathrm{pH}$ and of was the most affected.
\end{abstract}

Keywords: Drug delivery systems; chitosan; emulsion polymerization; graft copolymers.

Submitted: July 09, 2021. Accepted: December 08, 2021.

Cite this: Küçükçalık A, Ünlü $\mathrm{CH}$. Chitosan-graft-Polyacrylamide Based Release Systems: Effect of pH and Crosslinking. JOTCSA. 2022;9(1):121-30.

DOI: https://doi.org/10.18596/jotcsa.968037.

*Corresponding author. E-mail: unlucu@itu.edu.tr.

\section{INTRODUCTION}

Chitosan is the second most abundant macromolecule in nature after cellulose. It has many aspects being biocompatible, biodegradable, non-toxic, convenient to modification, etc $(1,2)$. It has a linear structure which is composed of $1,4-\beta-2-$ amino-2-deoxy-D-glucose (deacetylated Dglucosamine) and $\mathrm{N}$-acetyl-D-glucosamine units. Chitosan is obtained by deacetylation of chitin; in fact, chitin and chitosan are only different in degree of deacetylation (DDA); when DDA is higher than $50 \%$ the biopolymer is called as chitosan, otherwise as chitin. The structural features such as crystallinity and solubility are also very closely related with DDA, i.e. chitin and chitosan portions of the 50\% DDA biopolymer form an amorphous block copolymer while $99 \%$ DDA is a linear, random semicrystalline copolymer (3). Solubility also increases with increasing DDA; amine groups of the chitosan has a pK value of approximately 6.5 indicating that if the medium $\mathrm{pH}<4$ chitosan is soluble forming a polycationic structure (3-5).

Ceric ion initiated polymerizations are widely used for aqueous grafting vinyl polymers onto reducing agents which has one or more $\mathrm{O}-\mathrm{H}$ groups (6), i.e. PEG (7), cellulose $(8,9)$, and xylan (10). Initiation step involves oxidation of $\mathrm{O}-\mathrm{H}$ groups through a radical pathway. First, ceric ion and reducing agent (i.e. cellulose) form a 5-membered chelate complex; then in acidic medium this complex decomposes, creating a radical on either carbon or oxygen, reducing $\mathrm{Ce}(\mathrm{IV})$ to $\mathrm{Ce}$ (III) (9). The creation of radicals is a set of complex equilibria including the concentrations of components, temperature and 
duration of the reaction. If these factors are not set properly reaction may lead to oxidation of reducing compound terminating the radical created (i.e. low polymer yield). Another problem may be selfcreation of radical from air oxygen or from solvent (water) leading to homopolymers. In order to prevent the mentioned side effects an optimum condition has to be found. Having active sites chitosan also can react with ceric ion like cellulose and other polysaccharides $(11,12)$.

Controlled release systems or controlled drug delivery systems are used for delivering some therapeutic agent at a certain site or releasing it slowly in the body; thus the agent is needed to incorporate to a polymeric network structure (13). Chitosan is widely preferred for controlled release systems especially due to unique properties which are mentioned above including biocompatibility and swelling behavior at low pH $(1,13)$. After modification with polyacrylamide swelling property of chitosan enhances and this copolymer may be used as a matrix which become very popular component for controlled release systems. There are many parameters affecting swelling, and in turn release behavior, of the copolymer; some of these parameters are $\mathrm{pH}$, temperature, concentration, and salinity $(2,14,15)$. Chitosan-polyacrylamide release matrix is used in earlier studies with several differences, for example Bulut has used chitosangraft-polyacrylamide matrix supporting with carboxymethylcellulose to encapsulate and release ibuprofen (12), and Wang et al. has grafted polyacrylamide and poly( $\mathrm{N}$-isopropylacrylamide) to chitosan to use obtain a gel structure both sensitive to $\mathrm{pH}$ and temperature (16). Presence or number of crosslinks among the copolymer which is grafted onto chitosan chains may affect the release rate in media with different $\mathrm{pH}$ values.

In this study, chitosan functionalization via redox polymerization using ceric ammonium nitrate as initiator to graft linear or crosslinked polyacrylamide moieties onto chitosan has aimed in order to obtain controlled release systems. First, optimization of the reaction conditions was achieved. Then spectral and physical characterizations of the samples was done. Finally, controlled release experiments were done at different $\mathrm{pH}$ values which were corresponding to different environmental values as acidic $(\mathrm{pH} 2$, stomach), nearly neutral ( $\mathrm{pH} 6$, skin), and basic $(\mathrm{pH}$ 8.5, intestine).

\section{MATERIALS AND METHODS}

Chemicals and solutions

Chitosan 99\% DDA (Sigma Aldrich), nitric acid $(65 \%, d=1.40 \mathrm{~g} / \mathrm{mL}$, Merck), acrylamide (AAm) (Merck), methylenebisacrylamide (MBA) (Fluka), sodium hydroxide (Merck), acetylsalicylic acid (ASA) (Sigma-Aldrich), glacial acetic acid (Merck), isopropyl alcohol (technical grade, distilled prior to every use), acetone (Merck). Rest of the chemicals were all of Merck brand and used as received.

Ceric ammonium nitrate (CAN) was Sigma-Aldrich brand and it was used as a stock solution of $0.05 \mathrm{M}$ in $0.1 \mathrm{M}$ nitric acid.

Acidic buffer solution ( $\mathrm{pH} 2)$ was prepared dissolving $\mathrm{KCl}(7.45 \mathrm{~g})$ in water; then $\mathrm{HCl}(37 \%, 1.75 \mathrm{~mL})$ was added to the mixture and completed to $1.0 \mathrm{~L}$ with distilled water.

Slightly acidic buffer solution ( $\mathrm{pH} 6)$ was prepared dissolving $\mathrm{Na}_{2} \mathrm{HPO}_{4} .7 \quad \mathrm{H}_{2} \mathrm{O} \quad(1.307 \mathrm{~g})$ and $\mathrm{NaH}_{2} \mathrm{PO}_{4} \cdot \mathrm{H}_{2} \mathrm{O}(13.127 \mathrm{~g})$ in water; then the mixture completed up to $1.0 \mathrm{~L}$ with distilled water.

Basic buffer solution ( $\mathrm{pH}$ 8.5) was prepared dissolving $\mathrm{H}_{3} \mathrm{BO}_{3}(61.83 \mathrm{~g})$ and $\mathrm{NaOH}(10.00 \mathrm{~g})$ in water; then the mixture completed to $1.0 \mathrm{~L}$ with distilled water.

\section{Instruments}

FTIR measurements were carried out on Thermo Scientific Nicolet 380 equipped with a diamond crystal ATR module in a range of $4000-400 \mathrm{~cm}^{-1}$ in percent transmission mode.

NMR measurements were carried out on an Agilent instrument (500 $\mathrm{MHz}$ for ${ }^{1} \mathrm{H}, 11.7 \mathrm{~T}$ ) using $\mathrm{D}_{2} \mathrm{O}$ as solvent.

UV-visible spectra were taken on Perkin Elmer Lambda 25 model instrument in 200-400 nm wavelength range.

\section{Molecular weight determination}

Molecular weight determinations were carried out using viscometric method with Ubbelohde viscometer. Mark-Houwink constants for polyacrylamide was $\mathrm{K}=6.31 \times 10^{-3} \mathrm{~mL} / \mathrm{g}$ and $\mathrm{a}=$ 0.80 in water at $30^{\circ} \mathrm{C}$. (17) Intrinsic viscosity ( $[\eta]$

) was determined using Solomon-Ciuta equation (1). $(18,19)$

$$
[\eta]=\frac{\sqrt{2-\left(\eta_{s p}-\ln \eta_{\text {rel }}\right)}}{C}
$$

\section{Thermogravimetric analyses}

Thermogravimetric analyses (TGA) were carried out on a Perkin Elmer Pyris 1 TGA with a heating rate of $20^{\circ} \mathrm{C} / \mathrm{min}$ in $30-1000^{\circ} \mathrm{C}$ range.

\section{Statistical analysis}

Principal component analysis (PCA) was performed on first derivative FTIR data using $R$ software (version 4.0.0) running on 64-bit MS Windows 10 platform. First order derivatives of the spectra in range between 1800 and $850 \mathrm{~cm}^{-1}$, which were calculated via the Savitzky-Golay algorithm averaging 4 points left and right side using a third 
order polynomial, were used in order to eliminate the errors that could arise from overlapping.

\section{Synthesis of Chitosan-graft-Poly(Acrylamide) (ChAAm)}

Chitosan $(0.1 \mathrm{~g})$ and AAm $(0.5 \mathrm{~g})$ were dissolved in $10 \mathrm{~mL} 1 \%$ acetic acid separately in 15 minutes at $40{ }^{\circ} \mathrm{C}$; then both solutions were mixed to have a chitosan:AAm mass proportion of 1:5. After stirring at $40{ }^{\circ} \mathrm{C}$ for another 15 minutes $6 \mathrm{~mL}$ of $\mathrm{CAN}$ solution was slowly added to the mixture in 15 minutes. Polymerization was allowed to continue for 3 hours at the same temperature. Then the mixture was poured into 5 volumes of isopropanol to precipitate grafted copolymer. The medium $\mathrm{pH}$ was adjusted with to approximately 9 with $1 \mathrm{M} \mathrm{NaOH}$; then the alcoholic mixture was left to precipitate the small chains overnight at $-35{ }^{\circ} \mathrm{C}$. The graft copolymer was separated centrifuging at 200-G for 5 minutes, then left to dry first in air, then in the vacuum.

The percentage (G\%) and efficiency (E\%) of grafting was calculated as following equations (2) and (3). (11)

$$
\begin{aligned}
& G \%=\frac{W_{\text {cop }}-W_{\text {chitosan }}}{W_{\text {chitosan }}} \times 100 \\
& E \%=\frac{W_{\text {cop }}-W_{\text {chitosan }}}{W_{\text {monomer }}} \times 100
\end{aligned}
$$

\section{Synthesis of Crosslinked Grafted Copolymer (ChAAx)}

Polymerization procedure for crosslinked copolymers was similar, but after addition of CAN solution methylenebisacrylamide (MBA) was added to the mixture as crosslinking agent in different proportions relative to AAm. The proportions of AAm:MBA were $15: 1,20: 1,30: 1$, by mass. The termination and precipitation parts of the procedure was followed likewise.

\section{Loading and Releasing Acetyl Salicylic Acid}

Loading of ASA was carried out using polyelectrolyte complex (PEC) method. The copolymer (108 mg) was dissolved in $10 \mathrm{~mL}$ of $1 \%$ acetic acid; in another container acetylsalicylic acid (ASA) was dissolved in $10 \mathrm{~mL}$ of water, then it was made alkaline with addition of $1 \mathrm{M} \mathrm{NaOH}$. The alkaline ASA solution was dripped slowly into acidic copolymer solution in 10 minutes. Afterwards, the ASAcopolymer mixture was poured into acetone solution to precipitate. In order to accelerate and promote precipitation the final solution was cooled in deep freeze $\left(-25^{\circ} \mathrm{C}\right)$. The loaded copolymers were collected centrifuging the cold mixture. The loaded samples were washed with acetone, dried first in air, then in vacuum. Then the loaded copolymer was pressed to convert into a pellet.

Release of ASA from the copolymer matrix was monitored using UV-visible spectroscopy using the intensity of the signal located at $300 \mathrm{~nm}$. First calibration curves were obtained for ASA at 3 different $\mathrm{pH}$ using proper buffer solutions. Then the loaded copolymer was placed in a container with 10 $\mathrm{mL}$ appropriate buffer solution and UV measurements were done periodically.

\section{RESULTS AND DISCUSSIONS}

Chitosan is a naturally occurring polymer and is mainly composed of $\beta$-2-amino-anhydroglucose units linked through 1 to 4 positions. Having active $\mathrm{OH}$ sites chitosan reduces ceric ion, creating radicals with a redox reaction leading to initiation of a vinyl polymerization (6). Radical generation from cellulose is related with a chelate complex formation $(8,9)$. Thus a similar path is expected for chitosan; the formed radical may be on nitrogen, oxygen, or carbon (Figure 1). 


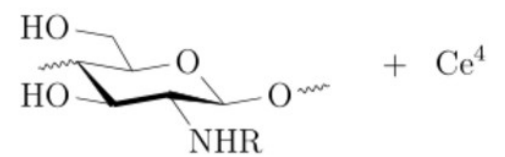

1,4-Anhydroaminoglucose

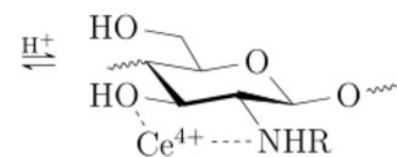

Chelate complex<smiles>[Y10]CC(OC)OC(CO)C(=O)CC</smiles>

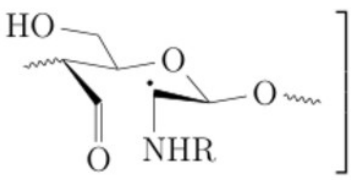

or<smiles>[R12]C(O[CH])OC(CO)CO</smiles>

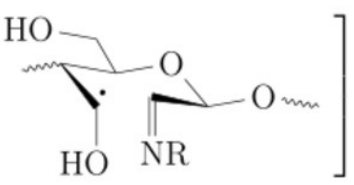

Figure 1: Plausible mechanism of radical generation with ceric ion and chitosan.

Although a reducing agent is needed to create radicals, sometimes ceric ion and aerial oxygen (or water) can also react to produce radicals, leading to homopolymers. The possible reactions were given in the scheme below. This unfavorable situation can be prevented adjusting reaction conditions. Other unwanted side reactions involving reducing agent, chitosan, were degradation in acidic medium or oxidation by ceric ion.

\section{Radical generation}

$$
\begin{aligned}
& \mathrm{Ch}-\mathrm{H}+\mathrm{C} \mathrm{\textrm {e } ^ { 4 + } \rightarrow}[\text { Complex }] \rightarrow C h \cdot+\mathrm{Ce}^{3+}+\mathrm{H}^{+} \\
& \mathrm{M}+\mathrm{C} e^{4+} \rightarrow \mathrm{M} \cdot+\mathrm{Ce}^{3+}+\mathrm{H}^{+}
\end{aligned}
$$

\section{Chain initiation}

$$
\begin{aligned}
& C h \cdot+M \rightarrow C h-M \cdot \\
& M \cdot+M \rightarrow M-M \cdot
\end{aligned}
$$

$$
\begin{aligned}
& \text { Propagation } \\
& C h-M \cdot+(n-1) M \rightarrow C h-M_{n} . \\
& M-M \cdot+(m-2) M \rightarrow M_{m} .
\end{aligned}
$$

\section{Termination}

$$
\begin{aligned}
& C h-M_{n} \cdot C h-M_{m} \cdot \rightarrow \text { Graft copolymer } \\
& C h-M_{n} \cdot+M_{m} \cdot \rightarrow \text { Graft copolymer } \\
& M_{m} \cdot M_{m} n \cdot \rightarrow \text { Homopolymer } \\
& C h \cdot+C e^{4+} \rightarrow \text { Oxidation products } \\
& C h-M_{n}+C e^{4+} \rightarrow \text { Oxidation products }
\end{aligned}
$$

Scheme 1: Possible reactions in the medium containing chitosan ( $\mathrm{Ch}), \mathrm{CAN}\left(\mathrm{Ce}^{4+}\right)$, and monomer (AAm, MBA).

Ceric ion initiated polymerization reactions were affected by several factors including total acid concentration, reducing agent type, concentrations, reaction temperature, and duration $(7,20,21)$. These factors were interfering among each other; thus an optimization run was necessary for different monomer and/or reducing agent couples to have a maximum yield of desired product, i.e. graft copolymer. As previous studies implied each factor had an individual apex interfering with each other starting with a predetermined condition obtained from earlier works was favorable $(7,8,10)$.

Releasing experiments were carried out in $1 \%$ acetic acid in order to carry out the reaction in a homogeneous solution as chitosan was soluble in acidic solutions. As the results indicated that using inert atmosphere was not needed. Changes in temperature and/or reaction period caused a decrease in $\mathrm{G} \%$ and $\mathrm{E} \%$. Optimum conditions were determined as $40{ }^{\circ} \mathrm{C}, 3.85 \mathrm{~g} / \mathrm{L}$ chitosan, $0.27 \mathrm{M}$ AAm; CAN proportions were used as $6 \mathrm{mmol} C A N$ per gram chitosan, and $43 \mathrm{mmol}$ CAN per mol AAm. Under these conditions a G\% of $350 \%$ was observed (E\% was 70\%) and copolymer labelled as ChAAm.

Blank experiment (using the same conditions without chitosan) resulted in a reaction yield of $8 \%$. This result indicated that chitosan was needed to produce radicals to start the polymerization.

After determining optimum conditions crosslinked copolymers were synthesized using same parameters with addition of MBA as crosslinking agent at different amounts. AAm:MBA proportions were set as $15: 1,20: 1$, and $30: 1$ by mass; these proportions were corresponding to $33: 1,43: 1$, and 65:1 AAm:MBA by mole. The crosslinked copolymers were labelled as ChAAx-15, ChAAx-20, and $\mathrm{ChAAx}-30$ after their AAm:MBA proportions. Introduction of $M B A$ resulted in a decrease in obtained product amount in the first place. When a detailed examination was made it was seen that G\% was decreasing with an increase in AAm:MBA proportion. As the proportion was adjusted as 15:1, 
20:1, and 30:1 the G\% values were observed as 317,206 , and $157 \%$, respectively. Also, E\% was affected in a similar manner; it was observed as 60, 40, and $31 \%$ for ChAAx-15, ChAAx-20, and ChAAx30 while it was $70 \%$ for ChAAm. This occurrence was probably due to crosslinks of MBA were both amongst acrylamide chains and chitosan chains at the same time.

\section{Characterizations of Graft Copolymers}

Molecular weight determinations were done utilizing the viscometric method. Intrinsic viscosity, and in turn molecular weight of the copolymers, was determined by Solomon-Ciuta and Mark-Houwink equations, respectively. Mark-Houwink constants $\left(6.31 \times 10^{-3} \mathrm{~mL} / \mathrm{g}\right.$ and $\left.\mathrm{a}=0.80\right)$ belong to polyacrylamide in aqueous solution at $30{ }^{\circ} \mathrm{C}$ (17). Although this method could not give the absolute molecular weight, it might give useful information about the samples for comparitive purposes. The molecular weight of ChAAm was determined as $55 \mathrm{kDa}$ while increasing MBA component caused a decrease; molecular weight of $\mathrm{ChAAx}-15$ was 17
$\mathrm{kDa}$, it was measured as $12 \mathrm{kDa}$ for ChAAx-20 and as $10 \mathrm{kDa}$ for ChAAx-30.

Characteristic FTIR signals that were related to chitosan were summarized as $\mathrm{O}-\mathrm{H}$ and $\mathrm{N}-\mathrm{H}$ stretching vibrations (overlapped) as a broad signal with peak positions at 3357 and $3282 \mathrm{~cm}^{-1}$, various $\mathrm{C}-\mathrm{H}$ stretching vibrations with a peak at $2870 \mathrm{~cm}^{-1}$. Amide I and/or adsorbed water vibrations were observed at $1644 \mathrm{~cm}^{-1}$, amide II vibration at 1566 $\mathrm{cm}^{-1}$, various $\mathrm{C}-\mathrm{C}-\mathrm{H}, \mathrm{C}-\mathrm{O}-\mathrm{C}, \mathrm{C}-\mathrm{C}-\mathrm{O}$ bending, and $\mathrm{C}-$ C, C-O stretching vibrations between $1500-800 \mathrm{~cm}^{-}$ 1. The signal at ca. $899 \mathrm{~cm}^{-1}$ belonged to the anomeric $\left(C_{1}\right)$ region of the chitosan indicating $\beta$ conformation (5).

The FTIR spectrum of obtained copolymer (ChAAm) displayed characteristic signals of polyacrylamide besides chitosan; stretching vibrations at 3341 and $3206 \mathrm{~cm}^{-1}$, amide $\mathrm{C}=\mathrm{O}$ stretching (amide I) at 1660 $\mathrm{cm}^{-1}$, bending (amide II) at $1621 \mathrm{~cm}^{-1}$, stretching (amide III) at $1422 \mathrm{~cm}^{-1}$ (22) (Figure 2).

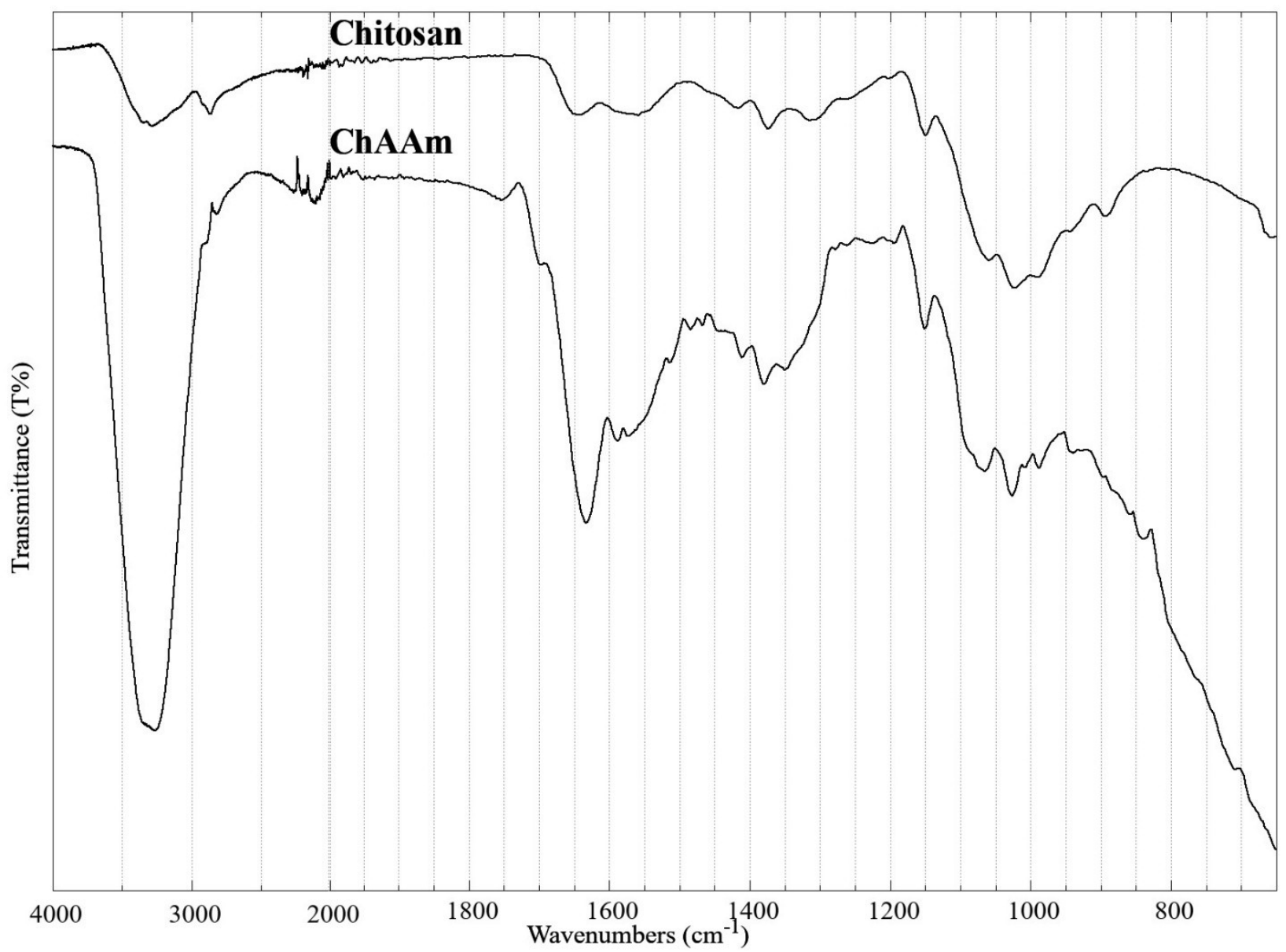

Figure 2: FTIR spectra of chitosan and ChAAm copolymer.

Comparison of FTIR spectra belonging to chitosan and ChAAm indicated that grafting of polyacrylamide onto chitosan was achieved. Crosslinking agent, MBA, caused a broadening in amide I, and II signals, also an additional signal at amide III region was observed. As these signals appeared with introduction of MBA it was thought that crosslinked copolymers were obtained. 
Additionally, $C_{1}$ related signal was observed around $895 \mathrm{~cm}^{-1}$ for crosslinked copolymer indicating a slight conformational relaxation on chitosan backbone.

FTIR spectra of chitosan and acrylamide copolymers were quite similar in many aspects. Moreover, $\mathrm{C}=\mathrm{O}$ stretching vibrations of acrylamide moieties overlapped with chitosan signals. In order to identify and characterize copolymers a statistical method, PCA, was applied to the FTIR data. Sampling a typical FTIR spectrum several hundreds of points in correlation to each other stored. Applying PCA this correlation was removed creating uncorrelated variates known as principal component (PC) scores. The PCs could be defined as new, orthogonal axes where variances were maximized. Thus, the projection of PCs against one another could reveal the clustering or structural information regarding the major components that are responsible for the change in certain region of the spectrum.

The scores plot of the first three PCs, which together account for $99 \%$ of total variance, was shown in Figure 3. In the plot PC1 and PC3 were used as $\mathrm{x}$ - and $\mathrm{y}$ - axes, respectively, same colors indicating near-by groups in PC2. Chitosan appeared nearly at the center of the plot while ChAAm was observed at the right-hand side of PC1. As this occurrence was related with grating a detailed analysis on loadings plot of the PCs indicated that positions on the plot were mainly related with amide $\mathrm{C}=\mathrm{O}$ stretching vibration (from $\mathrm{AAm}$ ) around 1670 $\mathrm{cm}^{-1}$ and $\mathrm{C}-\mathrm{O}$ (of chitosan backbone) related signals in $1300-900 \mathrm{~cm}^{-1}$ range. Introduction of crosslinking agent resulted in shifts on PC3 while slight changes were observed or PC1. This result also supported that the presence of MBA leads to more crosslinked structures than grafting onto chitosan backbone.

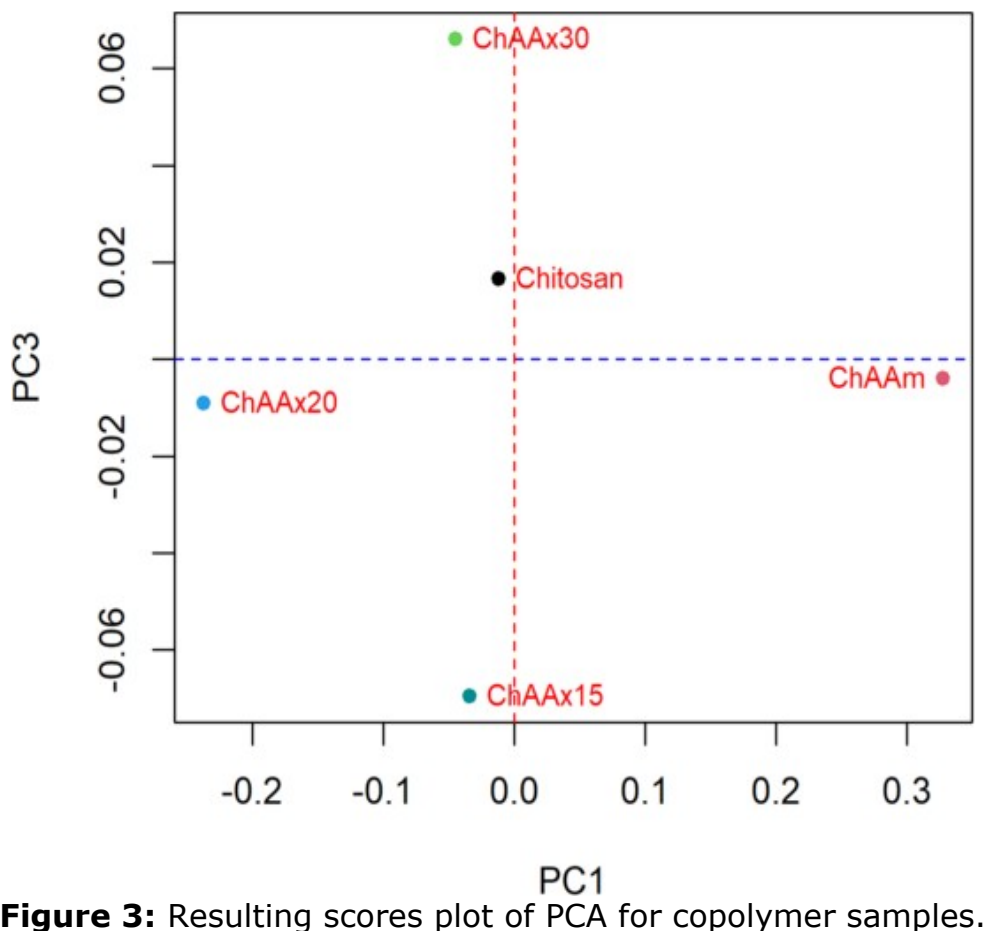

Thermal characterizations of copolymers were carried out using TGA. First loss was due to adsorbed water, and was observed as a broad signal starting around $40{ }^{\circ} \mathrm{C}$ and ended around $150{ }^{\circ} \mathrm{C}$ with a proportion of 10 to $15 \%$. This loss had a maximum weight loss temperature, $\mathrm{T}_{\mathrm{H} 2 \mathrm{O}}$, observed at $101{ }^{\circ} \mathrm{C}$ for chitosan. Then another degradation was observed between 250 and $430{ }^{\circ} \mathrm{C}$; the maximum degradation temperature, $T_{\max }$, for this event was also determined from derivative TGA (DTGA) plot as $334^{\circ} \mathrm{C}$.

Introduction of polyacrylamide moiety onto chitosan backbone resulted in an increase in $\mathrm{T}_{\mathrm{H} 2 \mathrm{O}}$; it was observed as $125{ }^{\circ} \mathrm{C}$ for ChAAm. In addition, an increase in the intensity of derivative peak indicated that introduction of polyacrylamide moieties increased the water uptake of the copolymer as expected. The second decomposition, which was related, with mainly decomposition of polyacrylamide portion observed between 250 and $400{ }^{\circ} \mathrm{C}$ with a peak position at $300{ }^{\circ} \mathrm{C}$ in DTGA. There was also an additional signal maximum in DTGA located at $487^{\circ} \mathrm{C}$ that was related with the second stage decomposition of polyacrylamide.

Crosslinked copolymers displayed slightly higher values for each thermal event. Water loss signal was observed as $112{ }^{\circ} \mathrm{C}$ for ChAAx-15, $130{ }^{\circ} \mathrm{C}$ for ChAAx-20, and $93{ }^{\circ} \mathrm{C}$ for ChAAx-30. Polyacrylamide decomposition pattern was observed in the same range with ChAAm; however, maximum degradation 
temperatures were changing according to AAm:MBA ratio. ChAAx-15 and $C h A A x-30$ had a small signal around $280{ }^{\circ} \mathrm{C}$ and a stronger signal peaked around $310^{\circ} \mathrm{C}$ which was very close to the peak signal for ChAAm. However, ChAAx-20 displayed two distinct signals in this range one was located around $330^{\circ} \mathrm{C}$ and another at $386^{\circ} \mathrm{C}$. The shape pattern was also different for this decomposition. This occurrence was probably due to different amounts of crosslinking in the structure.

\section{Release Experiments}

Controlled release experiments were done using 4 different copolymer matrices (ChAAm, ChAAx-15, ChAAx-20, ChAAx-30) at 3 different pHs $(2,6$, and 8.5). Releasing material was acetylsalicylic acid (ASA). The experiments were carried out at ambient temperature; ASA:copolymer proportion were kept constant at $1: 3$ by mass. ASA was loaded to the copolymer matrix using polyelectrolyte complex (PEC) method. In this method, ASA was encapsulated by copolymer matrix.

After preparation the pellets were placed in corresponding buffer solutions for $\mathrm{pH} 2,6$, or 8.5. The $\mathrm{pH}$ selection of the buffers was done for imitating the medium of stomach (strongly acidic), skin (weakly acidic or nearly neutral), and intestine (basic) for in vitro studies, respectively. In order to monitor the release of ASA calibration measurements were done separately in corresponding buffer solutions. The collected data was evaluated in two ways: the effect of the crosslinking at the same $\mathrm{pH}$ (Figure 4), and the effect of the $\mathrm{pH}$ for same matrix (Figure 5).

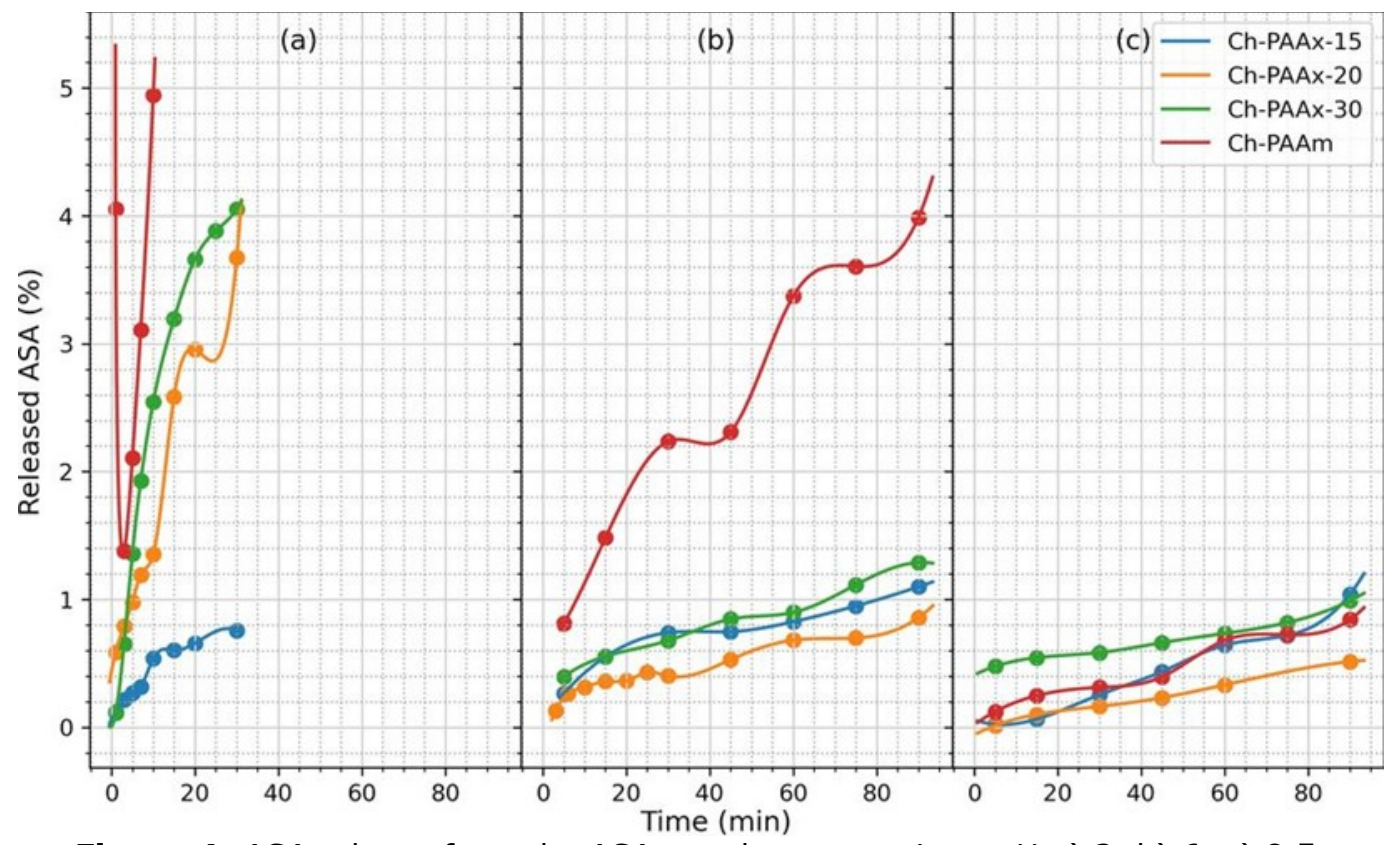

Figure 4: ASA release from the ASA:copolymer matrix at $\mathrm{pH}$ a) 2, b) 6, c) 8.5 . 


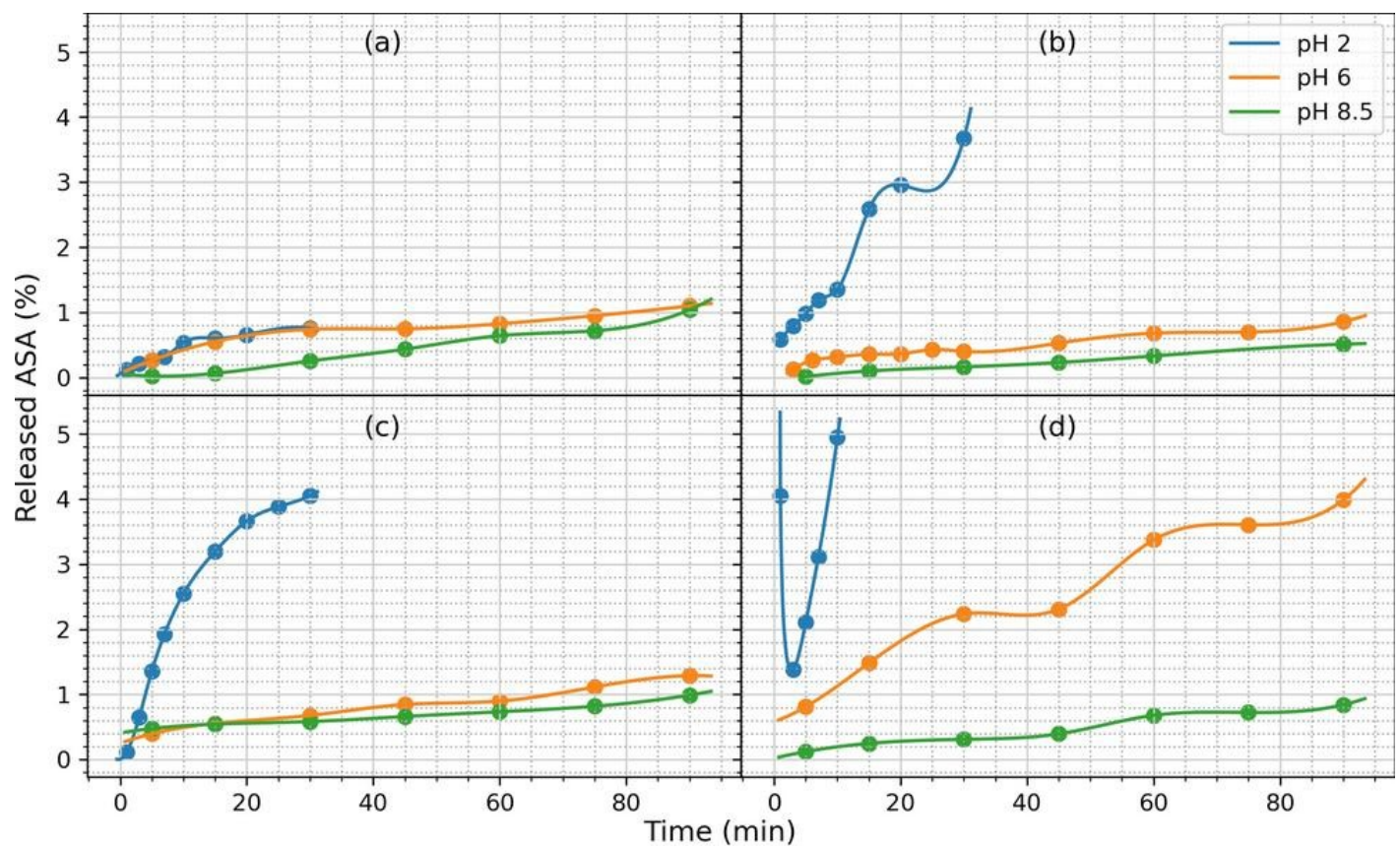

Figure 5: ASA release from the ASA:copolymer matrix based on a) ChAAx-15, b) ChAAx-20, c) ChAAx-30, d) ChAAm.

The UV-visible spectrum of ASA displayed several absorption bands within the wavelength range of 200-450 nm. The strongest signals were located around $200 \mathrm{~nm}$ with two peak positions one was located around $215 \mathrm{~nm}$, and the other was at 225 $\mathrm{nm}$. This distinction was clear for $\mathrm{pH} \mathrm{2,} \mathrm{but} \mathrm{for} \mathrm{other}$ $\mathrm{pH}$ values $225 \mathrm{~nm}$ signal lost intensity and became a shoulder to $215 \mathrm{~nm}$. Another strong signal was located at $300 \mathrm{~nm}$. All signals were shifted insignificantly as a result of changing medium $\mathrm{pH}$. Chitosan displayed a signal only around $200 \mathrm{~nm}$ due to amide carbonyl transitions especially for $\mathrm{pH} \mathrm{2,} \mathrm{in}$ the other two spectra this signal was observed slightly lower than $200 \mathrm{~nm}$, so only tailing part of the signal was seen. Thus, quantitative ASA measurements were taken using the signal at 300 $\mathrm{nm}$ in order to prevent interferences.

The release rate was influenced by medium acidity as the matrix was very sensitive to $\mathrm{pH}$ (Figure 4ac). Having $\mathrm{N}-\mathrm{H}$ groups with an approximate $\mathrm{pK}$ value of $6.5(4,5)$ chitosan backbone was expected to dissolve in acidic media. However, grafted polyacrylamide moieties retarded or prevented complete dissolution possibly due to extensive hydrogen bonding and/or crosslinking resulting in swelled structures. Increasing amount of MBA resulted in a structure with a higher number of crosslinks; thus, swelling behavior was influenced by composition.

For ChAAm, release behavior was extremely different from the rest of the samples at strongly acidic $\mathrm{pH}$. First, a high and rapid UV response was observed when the matrix was placed in release medium; then the response decreased until $1.4 \%$ and then increased again. A possible explanation for this event was fast expansion of the matrix in acidic medium. In this case, hydrogen bonds were the only interaction holding the matrix together; when dissolution occurred in the buffer, the loaded ASA was released at once in an uncontrolled fashion. However, later the dissolved polymer chains readsorbed ASA leading to a decrease in the UV absorption and then release of ASA was started again at a lower rate.

Unlike ChAAm, crosslinked copolymers displayed a more stable release behavior as expected. All crosslinked copolymers displayed a linear model for release, except ChAAm-20 that released ASA displaying a logarithmic model. Among the crosslinked copolymers, the slowest release was observed for ChAAx-15, which had the highest MBA proportion thus the highest number of crosslinks. This was expected, as intensive number of crosslinks caused the smallest pore size of the matrix; thus, ASA was released slower via these pores of the swelled matrix at a small rate. At this $\mathrm{pH}$ ChAAx-30 was also displayed a similar behavior indicating even a small number of covalently bonded crosslinks was affecting the swelled structure and its pore size as the matrix did not disperse easily in the medium and standing together forming up a swelled structure. Then ASA should permeate through the pores of this swelled structure. ChAAx-20 and ChAAx-30 displayed similar results with an exception in release model. When compared the release based on the component ChAAx-20 matrix was nearly linear while ChAAx-30 matrix was more a fit to logarithmic model.

When $\mathrm{pH}$ was changed to 6.0 release rate slowed down for all copolymers. Still being in a medium 
more acidic than pK value of chitosan, ChAAm based matrix displayed the highest release rate among them. The rest of the matrices displayed very close results. All matrices displayed an almost linear release model.

A similar result was also observed for $\mathrm{pH} 8.5$; this time even release from the matrix based on ChAAm was very close to the crosslinked copolymers.

At the same $\mathrm{pH}$ the difference in release behavior was due to swelling characteristics; as expected the smaller the pore size or the higher the number of crosslinks the slower the release rate.

In Figure 5a-d release behavior was shown as a function of copolymer composition; the release differences for the same copolymer at different $\mathrm{pH}$ values.

When the plots were evaluated, it was seen that $\mathrm{pH}$ clearly affected the release rate as well as composition of the copolymer. Amongst the copolymers, the slowest release was observed for ChAAx-15 regardless the medium acidic properties. It was the least affected matrix material due to extensive crosslinks of MBA.

Because of a decrease in MBA amount of the copolymer, corresponding to a decrease in crosslink intensity matrices became more sensitive to the medium $\mathrm{pH}$. ChAAx-20 and $\mathrm{ChAAx}-30$ gave very similar results; they released ASA rapidly in acidic medium while release was slowed down to similar values at higher $\mathrm{pH}$ values for both. The most sensitive matrix was ChAAm based; it was affected by medium $\mathrm{pH}$ dramatically. As mentioned above it released $A S A$ at once re-adsorbing and re-releasing it again at a slower rate in acidic medium. At $\mathrm{pH} 6$ release rate decreased and became more stable than acidic medium. In basic medium, the release rate decreased down to the lowest rate, which was very close to the rest of the copolymers.

\section{CONCLUSION}

ChAAm was synthesized with an efficiency of $68 \%$ corresponding to $340 \%$ grafting. Using determined condition crosslinked copolymers were synthesized with 15:1, 20:1, 30:1 mass proportions of AAm:MBA (ChAAx-15, ChAAx-20, ChAAx-30, respectively). The expectation was as the AAm:MBA proportion went higher MBA amount went lower resulting in a decrease in crosslinking. The results indicated that change in AAm:MBA proportion lead to different efficiency and grafting percentages. Thus, optimizing studies could be done for higher efficiency values for different proportions and/or a kinetic model would be determined.

The release behaviors of the prepared copolymers were monitored at 3 different $\mathrm{pH}$ values as 2, 6, and
8.5 for model media for stomach, skin, and intestine media, respectively. Loading ASA and monitoring release at different $\mathrm{pH}$ media indicated that the least $\mathrm{pH}$ sensitive matrix among these was ChAAx15 as it was stable and similar release behavior at all $\mathrm{pH}$ values, and the most $\mathrm{pH}$ sensitive was ChAAm as it had nothing but hydrogen bonds to hold the matrix together. According to the results, ChAAm based release matrices were suitable for skin-care applications while ChAAx-15 based ones were suitable for all $\mathrm{pH}$ values to release at a steady rate. Further studies could be done with different therapeutic agents, at different temperatures, and in vivo tests could be run.

\section{CONFLICT OF INTEREST}

The authors declare no conflict of interest.

\section{ACKNOWLEDGMENTS}

Authors thank to Istanbul Technical University Scientific Research Foundation for financial support.

\section{REFERENCES}

1. Shariatinia Z. Pharmaceutical applications of chitosan. Advances in Colloid and Interface Science. 2019 Jan;263:131-94. <DOI>.

2. Sahoo D, Sahoo S, Mohanty P, Sasmal S, Nayak PL. Chitosan: a New Versatile Bio-polymer for Various Applications. Designed Monomers and Polymers. 2009 Jan;12(5):377-404. <DOI>.

3. Barbosa MA, Gonçalves IC, Moreno PMD, Gonçalves RM, Santos SG, Pêgo AP, et al. 2.13 Chitosan. In: Comprehensive Biomaterials II [Internet]. Elsevier; 2017 [cited 2021 Dec 11]. p. 279-305. ISBN: 978-0-08-100692-4. <URL>.

4. Oyervides-Muñoz E, Pollet E, Ulrich $G$, de Jesús Sosa-Santillán G, Avérous L. Original method for synthesis of chitosan-based antimicrobial agent by quaternary ammonium grafting. Carbohydrate Polymers. 2017 Feb;157:1922-32. <DOI>.

5. Ünlü C, Pollet $E$, Avérous L. Original Macromolecular Architectures Based on poly $(\varepsilon-$ caprolactone) and poly( $\varepsilon$-thiocaprolactone) Grafted onto Chitosan Backbone. IJMS. 2018 Nov 29;19(12):3799. <DOI>.

6. Mino G, Kaizerman S. A new method for the preparation of graft copolymers. Polymerization initiated by ceric ion redox systems. J Polym Sci. 1958 Aug;31(122):242-3. <DOI>.

7. Atici OG, Akar A, Ayar Y, Mecit O. Synthesis of block copolymers via redox polymerization. J Appl Polym Sci. 1999 Feb 28;71(9):1385-95. <DOI>. 
8. Kalaoğlu Öİ, Ünlü CH, Galioğlu Atıcı O. Synthesis, characterization and electrospinning of corn cob cellulose-graft-polyacrylonitrile and their clay nanocomposites. Carbohydrate Polymers. 2016 Aug; 147:37-44. <DOI>.

9. Pottenger CR, Johnson DC. Mechanism of cerium (IV) oxidation of glucose and cellulose. J Polym Sci A-1 Polym Chem. 1970 Feb;8(2):301-18. <DOI>.

10. Ünlü $\mathrm{CH}$, Öztekin NS, Atıcı OG. Synthesis and thermal characterization of xylan-graftpolyacrylonitrile. Carbohydrate Polymers. 2012 Oct;90(2):1120-6. <DOI $>$.

11. Zohuriaan-Mehr M. Advances in Chitin and Chitosan Modification through Graft Copolymerization: A Comprehensive Review. Iranian Polymer Journal. 2005;14(3):235-65. <URL>.

12. Bulut E. Ibuprofen microencapsulation within acrylamide-grafted chitosan and methylcellulose interpenetrating polymer network microspheres: Synthesis, characterization, and release studies. Artificial Cells, Nanomedicine, and Biotechnology. 2015 Mar 6;1-11. <DOI>.

13. Bhattarai N, Gunn J, Zhang M. Chitosan-based hydrogels for controlled, localized drug delivery. Advanced Drug Delivery Reviews. 2010 Jan;62(1):83-99. <DOI>.

14. Martinez-Ruvalcaba A, Sanchez-Diaz JC, Becerra F, Cruz-Barba LE, Gonzalez-Alvarez A. Swelling characterization and drug delivery kinetics of polyacrylamide-co-itaconic acid/chitosan hydrogels. Express Polym Lett. 2009;3(1):25-32. <DOI>.
15. Prabaharan M. Review Paper: Chitosan Derivatives as Promising Materials for Controlled Drug Delivery. J Biomater Appl. 2008 Jul;23(1):536. $\leq \mathrm{DOI}>$.

16. Wang L, Jian Y, Le X, Lu W, Ma C, Zhang J, et al. Actuating and memorizing bilayer hydrogels for $a$ self-deformed shape memory function. Chem Commun. 2018;54(10):1229-32. <DOI>.

17. Scholtan von W. Molekulargewichtsbestimmung von Polyacrylamid mittels der Ultrazentrifuge. Makromol Chem. 1954;14(1):169-78. <DOI>.

18. Pamies R, Hernández Cifre JG, del Carmen López Martínez M, García de la Torre J. Determination of intrinsic viscosities of macromolecules and nanoparticles. Comparison of single-point and dilution procedures. Colloid Polym Sci. 2008 Sep;286(11):1223-31. <DOI>.

19. Solomon OF, Ciuta IZ. Détermination de la viscosité intrinsèque de solutions de polymères par une simple détermination de la viscosité. J Appl Polym Sci. 1962 Nov;6(24):683-6. <DOI>.

20. Akar A, Galioğlu O, Göçmen A, Sarac AS. Copolymer of ketonic resin-polyacrylonitrile. J Appl Polym Sci. 1990 Apr 20;39(8):1657-63. <DOI>.

21. Galioğlu O, Soydan AB, Akar A, Saraç AS. Block/graft copolymer synthesis via ceric salt. Angew Makromol Chemie. 1994 Jan;214(1):19-28. $\leq \mathrm{DOI}$.

22. Murugan R, Mohan S, Bigotto A. FTIR and polarised Raman spectra of acrylamide and polyacrylamide. Journal of the Korean Physical Society. 1998;32(4):505-12. 